\title{
Retained Gas Sampler Visualization Guide
}

\author{
A. Shekarriz
}

September 1994

Prepared for

the U.S. Department of Energy under Contract DE-AC06-76RLO 1830

Pacific Northwest Laboratory Operated for the U.S. Department of Energy by Battelle Memorial Institute 


\title{
DISCLAIMER
}

This report was prepared as an account of work sponsored by an agency of the United States Government. Neither the United States Government nor any agency thereof, nor Battelle Memorial Institute, nor any of their employees, makes any warranty, expressed or implied, or assumes any legal liability or responsibility for the accuracy, completeness, or usefulness of any information, apparatus, product, or process disclosed, or represents that its use would not infringe privately owned rights. Reference herein to any specific commercial product, process, or service by trade name, trademark, manufacturer, or otherwise does not necessarily constitute or imply its endorsement, recommendation, or favoring by the United States Government or any agency thereof, or Battelle Memorial Institute. The views and opinions of authors expressed herein do not necessarily state or reflect those of the United States Government or any agency thereof.

\author{
PACIFIC NORTHWEST LABORATORY. \\ operated by \\ BATTELLE MEMORIAL INSTITUTE \\ for the \\ UNITED STATES DEPARTMENT OF ENERGY \\ under Contract DE-AC06-76RLO 1830
}

Printed in the United States of America

Available to DOE and DOE contractors from the

Office of Scientific and Technical Information, P.O. Box 62, Oak Ridge, TN 37831; prices available from (615) 576-8401. FTS 626-8401.

Available to the public from the National Technical Information Service, U.S. Department of Commerce, 5285 Port Royal Rd., Springfield, VA 22161. 


\section{DISCLAIMER}

Portions of this document may be illegible in electronic image products. Images are produced from the best available original document. 
PNL-10138

UC-606

\section{Retained Gas Sampler Visualization Guide}

A. Shekarriz

September 1994

Prepared for the U.S. Department of Energy under Contract DE-ACO6-76RLO 1830

Pacific Northwest Laboratory Richland, Washington 99352 


\section{Executive Summary}

In a series of experiments performed in Phase II of the retained gas sampler visualization task, the effect of sampler tip geometry on waste sampling process has been investigated. From flow visualizations, which were captured on video, it is clear that disturbances on the surrounding fluid and the fluid entering the sampler were reduced as the tip changed from a flat to a sharper truncated cone shape. It has been shown, throughout this report, that deformation and disturbance of the waste is dominated by shape of the sampler tip, which moves the stagnation point, and not by viscosity of the fluid or sampling rate. 
. 


\section{Contents}

Executive Summary $\ldots \ldots \ldots \ldots \ldots \ldots \ldots \ldots \ldots \ldots \ldots \ldots$ ii

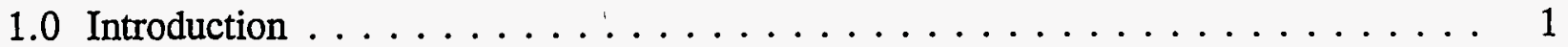

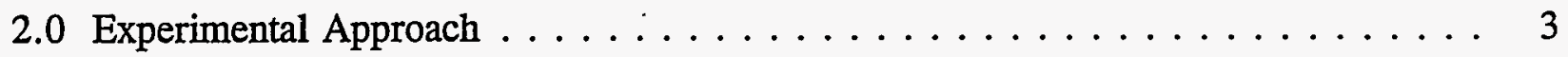

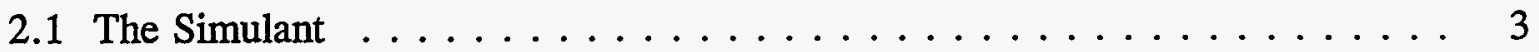

2.2 Sampler Bit Shapes . . . . . . . . . . . . . . . 3

3.0 Results and Discussion $\ldots \ldots \ldots \ldots \ldots \ldots \ldots \ldots \ldots \ldots$

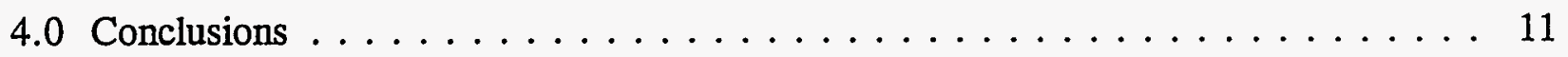

5.0 References ............................ 13 


\section{Figures}

1. Schematic Diagram of the Experimental Setup . . . . . . . . . . . . . . 4

2. Rheogram of the Three Mixtures Used in the RGS Visualization Tests ....... 5

3. Photograph of the Different Sampler Tip Geometries Tested . . . . . . . . . 6

4. A Simplified Flow Geometry in Which the Cylinder is Assumed Thin-Walled . . . . 8

5. Approximate Streamlines and Location of the Leading Edge

Stagnation Points for the Flat Tip and $60^{\circ}$ Tip Geometries,

Based on the Video Images . . . . . . . . . . . . . . . . . . . . . . . 10 


\subsection{Introduction}

The first phase of this task (Phase 1), which was completed in March of 1994, focused on performing some preliminary flow visualization tests. ${ }^{(a)}$ The goal was to gain a better appreciation of whether the current retained gas sampler (RGS) system performance is in line with the RGS concept and to identify some of the critical issues related to the RGS. These visualization tests clearly outlined the main fluid dynamics issues; that is, the sampler bit geometry can impact the sampling performance in two different ways: 1) the column of fluid extracted from the waste tank may not correctly represent the range of depth of insertion waste from which the fluid is sampled due to flow blockage and stretching of the fluid;2) the excessive disturbance of the waste immediately before sampling could result in poor sampling performance.

The primary objective of Phase II of the RGS visualization task was to investigate whether the sampling is rendered more effective as the geometry of the insertion end of the sampler changes from a blunt shape to a sharper leading edge. Secondary objectives were to investigate how the fluid viscosity and insertion rate affect the characteristics of sampling.

Throughout the course of this task the following experiments were performed:

- Bit Geometry Variation - blunt/flat tip, modified flat tip, $30^{\circ}, 45^{\circ}$, and $60^{\circ}$ truncated cone tips

- Velocity Variation - insertion rates ranging from $\sim 20 \mathrm{in} . / \mathrm{min}$ to $\sim 100 \mathrm{in} . / \mathrm{min}$

- Viscosity Variation - fluid viscosity ranging between $\sim 10^{5}$ and $\sim 10^{6} \mathrm{cP}$.

Section 2 is a discussion of the experiment and the approach that were used in performing this research. Section 3 contains the results that were achieved, and Section 4 describes the conclusions that were reached.

(a) Memorandum, A. Shekarriz, PNL, to K. R. Birney, B. J. Webb, and D. W. Wootan, WHC. April 26, 1994. Letter Report on RGS Visualization, Phase I Task. 



\subsection{Experimental Approach}

Figure 1 is a schematic diagram of the setup used for the visualization studies. A 5-foot-high clear acrylic tank, $12 \times 12$ inches in cross section, was used as a reservoir tank in which the simulant - sampler interaction was studied. The tank was filled with a transparent non-Newtonian simulant. A simple cable/pulley apparatus was used as an insertion mechanism for lowering the RGS cylinder into the simulant while keeping the inner piston of the RGS stationary. In order to overcome the buoyancy force acting on the sampler and assist the RGS cylinder in submersion, the cylinder was loaded with a set of dead weights at the top. As a result, the sampler had a tendency to translate through the simulant due to gravity. The insertion rate was controlled manually. Visualization of the behavior of the sampled simulant inside of the sampler was made possible by using a transparent acrylic tube.

\subsection{The Simulant}

The fluid used in these studies was a gel composed of $0.25 \%$ to $1.0 \%$ by weight of Carbopol $^{(b)} 980$ resin and water. Figure 2 displays the rheograms of the three mixtures. These rheograms were obtained from the simple viscometry tests performed on samples taken from the simulants and by using a Haake CV20 rheometer. ${ }^{(c)}$ This figure shows that the simulant has a shear thinning behavior and from the shear stress shear rate diagram (insert) the presence of a yield value greater than $2 \mathrm{~Pa}$ can be implied. The viscosity of the simulant at a shear rate of $0.1 \mathrm{~s}^{-1}$ appears to range between $150,000 \mathrm{cP}$ and $900,000 \mathrm{cP}$ for $0.25 \%$ and $1.0 \%$ by wt. mixtures, respectively. The yield of the material was the important feature of this waste, in addition to the fact that it was transparent, which allowed the simulant to retain gas bubbles of up to approximately $2.5 \mathrm{~cm}$ in diameter.

\subsection{Sampler Bit Shapes}

Figure 3 is a photograph of the five different sampler bit shapes, or geometries, that were tested: 1) the original flat tip, 2) the modified flat tip, 3) a $30^{\circ}$ tip angle; 4) a $45^{\circ}$ tip angle, and 5) a $60^{\circ}$ tip angle. The opening to the sampler tube is 1 inch in diameter, and the frontal area is $\pi / 4(2 \text { in. })^{2}$ in all cases. The main difference in the geometry of all the tips is

(b) Carbopol is a trademark of the B. F. Goodrich Company.

(c) Tests performed by L. K. Jagoda of the Engineering Technology Center at Pacific Northwest Laboratory. 
that the leading edge surface is horizontal for the flat and modified flat tips and $30^{\circ}$ to $60^{\circ}$ from the horizontal plane for the remainder of the tips, which creates a sharper and sharper leading edge.

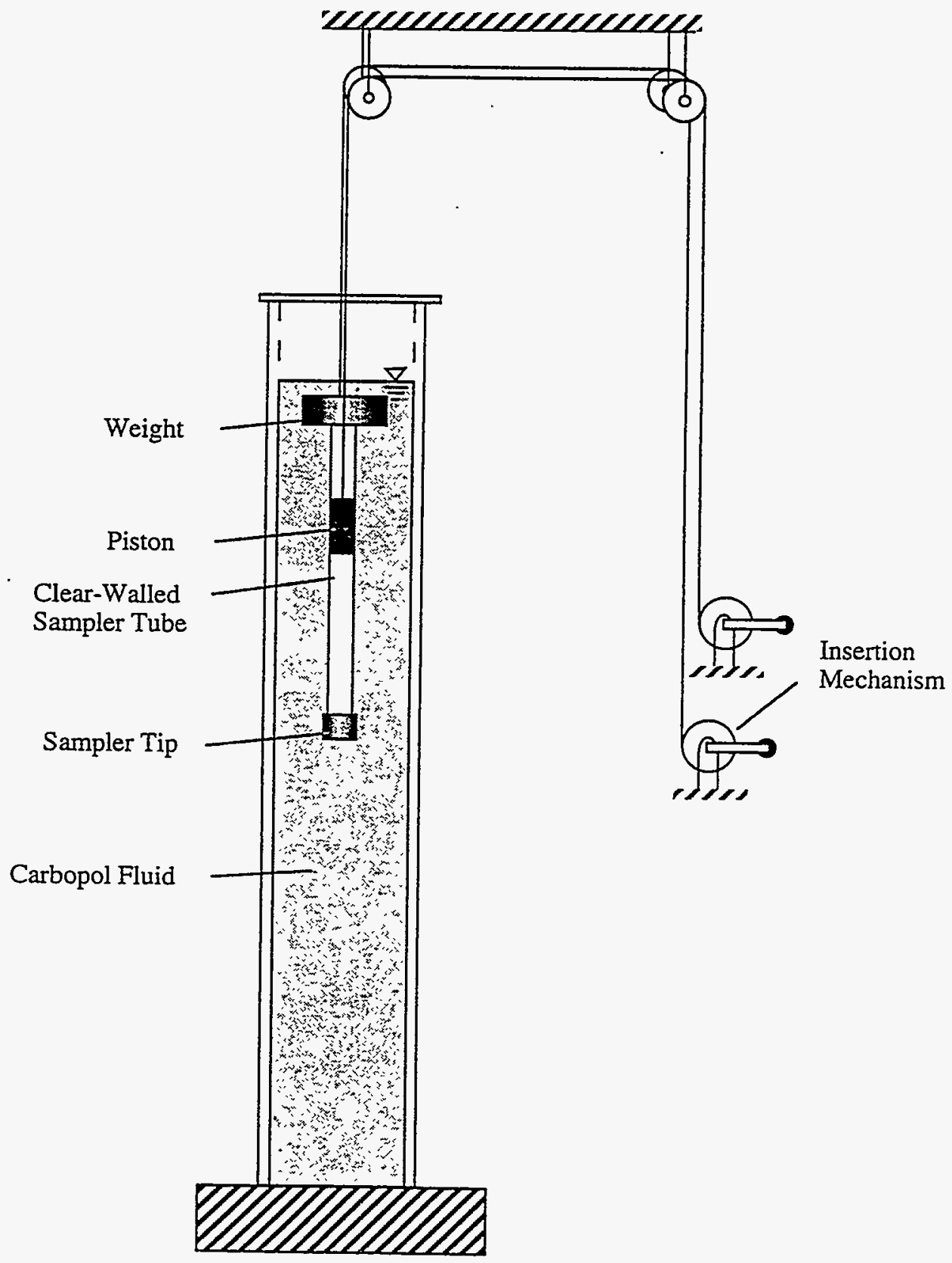

Figure 1. Schematic Diagram of the Experimental Setup 


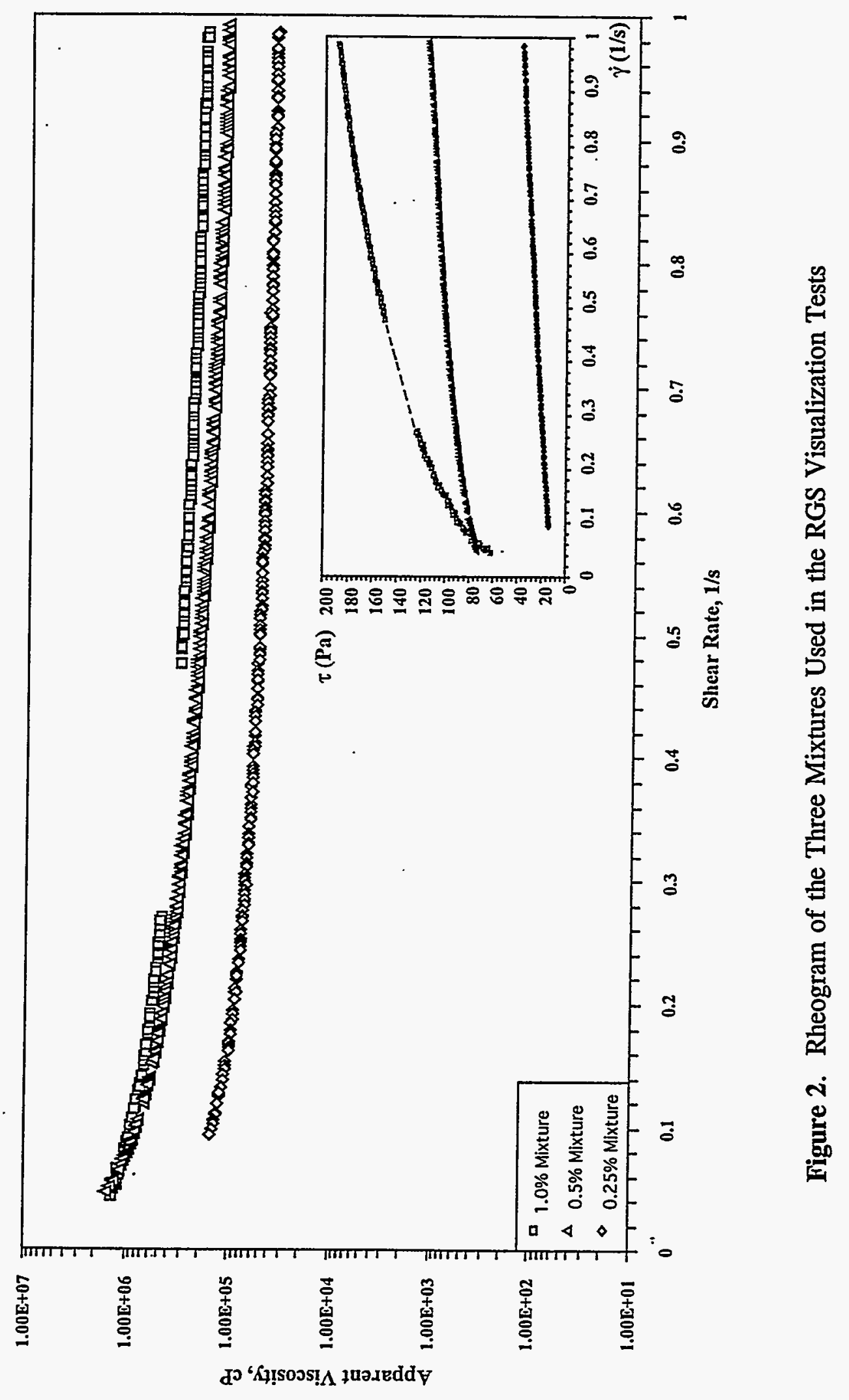




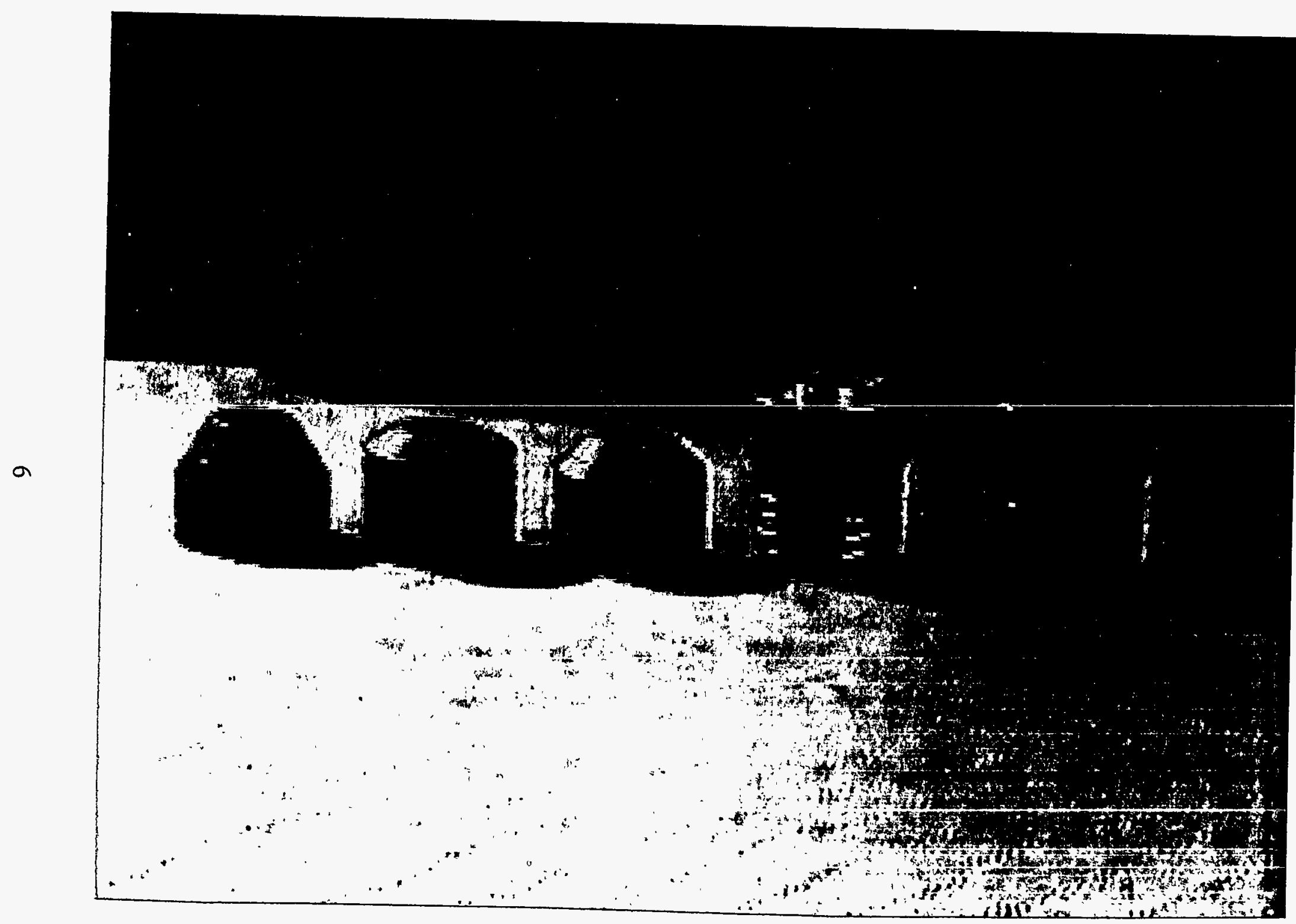

Figure 3. Photograph of the Different Sampler Tip Geometries Tested 


\subsection{Results and Discussion}

It is important to establish that two different parameters under investigation, velocity and viscosity, play little to no role in the performance of the sampler at these low insertion rates. The argument is based on the fundamentals of fluid mechanics. The equation of motion for a flow of a viscous fluid into an infinitely thin-walled axisymmetric cylinder, as shown in Figure 4, clearly demonstrates the point through theoretical basis. ${ }^{(d)}$ The momentum equation in the $\mathrm{x}$-direction can be written as

$$
\frac{\mathrm{D}}{\mathrm{Dt}}(\mathrm{pu})=-\frac{\partial \mathrm{p}}{\partial \mathrm{x}}+\frac{\mu}{\mathrm{r}} \frac{\partial}{\partial \mathrm{r}}\left(\mathrm{r} \frac{\partial \mathrm{u}}{\partial \mathrm{r}}\right)+\mu \frac{\partial^{2} \mathrm{u}}{\partial \mathrm{x}^{2}}
$$

where the term on the left side of the equation is an indication of the magnitude of the inertial forces, the first term on the right side is the magnitude of the static pressure gradient in the field, and the last two terms on the right side of the equation are the shear and normal stresses produced by the $x$-component of velocity (White 1977). If the above equation is nondimensionalized by dividing the velocity by $\mathrm{V}_{\infty}$, distances $\mathrm{x}$ and $\mathrm{r}$ by $\mathrm{d}$ (the diameter of the cylinder), and time $t$ by $d / V_{\infty}$, then the equation below will result where the superscript * indicates that the parameter is dimensionless.

$$
\frac{D}{D t *}\left(u^{*}\right)=-\frac{\partial\left(p / \rho V_{\infty}^{2}\right)}{\partial x^{*}}+\frac{1}{\operatorname{Re}_{\mathrm{d}}} \frac{1}{r^{*}} \frac{\partial}{\partial r^{*}}\left(\mathrm{r} * \frac{\partial \mathrm{u}^{*}}{\partial \mathrm{r}^{*}}\right)+\frac{1}{\mathrm{Re}_{\mathrm{d}}} \frac{\partial^{2} \mathrm{u}^{*}}{\partial \mathrm{x}^{*}}
$$

A close look at equation (2) shows that a parameter $\mathrm{Re}_{\mathrm{d}}$, which is the well-known Reynolds number, appears in the equation. Considering that the insertion rates, $V \infty$, are on the order of $20 \mathrm{in} . / \mathrm{min}$ (or approximately $1 \mathrm{~cm} / \mathrm{s}$ ), the diameter of the tube is on the order of 1 in. (or $2.5 \mathrm{~cm}$ ), and the apparent dynamic viscosity of the fluid is approximately $10^{5} \mathrm{cP}$, the Reynolds number becomes

$$
\operatorname{Re}_{\mathrm{d}} \equiv \frac{\rho \mathrm{V}_{\infty} \mathrm{d}}{\mu}=\frac{\left(10^{3} \mathrm{~kg} / \mathrm{m}^{3}\right)(0.01 \mathrm{~m} / \mathrm{s})(0.025 \mathrm{~m})}{(100 \mathrm{~kg} / \mathrm{m}-\mathrm{s})}=2.5 \times 10^{-3}
$$

Note that for the higher viscosity fluids used in these experiments, the Reynolds number is approximately one order of magnitude smaller, namely $\sim \mathrm{O}\left(10^{-4}\right)$. Because the

(d) For simplicity, the different flow regions, namely the inner flow $0<\mathrm{r}<\mathrm{R}$ and the outer flow $r>R$, each one having a different set of boundary conditions, will not be discussed. 


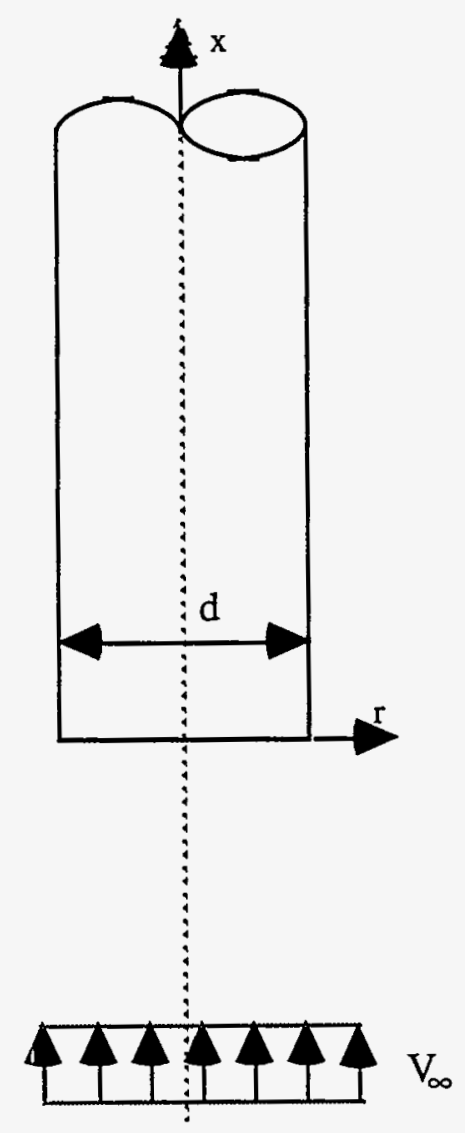

Figure 4. A Simplified Flow Geometry in Which the Cylinder is Assumed Thin-Walled

order of magnitude of all the remainder of the terms in the equation are $O(1)$, then the viscous terms, the second and third terms on the right side in equation (2), are much more dominant. This type of flow, where the Reynolds number is much smaller than 1 or $\mathrm{Re}_{\mathrm{d}}->0$, is known as Creeping flow, and it becomes independent of the Reynolds number. The equation that best describes the flow behavior in this regime is the biharmonic equation, as shown below:

$$
\nabla^{4} \Psi=0
$$

where $\Psi$ is the stream function. Because the equation in this regime, equation (4), is independent of the Reynolds number (provided that the Reynolds number is much smaller than 1), the flow (pattern) becomes similar for all $\mathrm{Re}_{\mathrm{d}}->0$, given the same geometry of flow. 
Although the sampler problem is complicated by the presence of the piston as an additional boundary condition in the $\mathrm{x}$-direction, making the problem elliptic, and by the existence of a finite leading edge, which produces a local stagnation flow at the front of the sampler, the problem still remains fairly similar because of the small Reynolds number. Video images of the flow field upstream of the sampler are the visual evidence of this argument. To verify this similarity in the flow field, the displacement of bubbles upstream of the sampler were measured as a function of the displacement of the sampler itself; i.e., as the sampler moves toward a bubble located directly upstream of the sampler, the bubble tends to move down with the sampler for a certain distance before the sampler catches up with it. It was observed that changes in the viscosity and insertion rate do not affect the ratio of the bubble displacement to the sampler displacement, keeping the tip geometry and the initial position of the bubble constant. Increasing the insertion rate only increases the rate at which this displacement takes place, and increasing the viscosity increases the resistance force on the sampler due to friction.

The stagnation point at the leading edge of the sampler moves as the leading edge geometry changes. As shown in Figure 5, the stagnation point moves inward toward the entrance of the sampler as the leading edge angle increases from 0 to $60^{\circ}$ from the horizontal axis. In the video one can see what happens to a relatively large bubble, on the order of 1 $\mathrm{cm}$ in diameter, when it approaches the stagnation point (Shekarriz 1994). Where a flat tip is used, the bubble is substantially stretched horizontally, and if the bubble is large enough, it breaks up and a large portion of the bubble is entrained into the sampler. Conversely, a bubble initially located in the same relative position to the sampler is not entrained into the sampler when the sampler tip is at a $60^{\circ}$ angle.

As a result of this change in the location of the stagnation point, the cross-sectional area of the fluid entering the sampler, $A_{f}$, represented by the area bounded by the lines of symmetry in the flow, approaches the cross-sectional area of the sampler, $A_{s}$. As the ratio $A_{f} / A_{s}-->1$, the amount of normal (compressive and elongational) stresses acting on the fluid upstream of the sampler is reduced. To minimize changes in the state of the waste prior to and during the sampling process, the magnitude of these normal stresses should be minimized.

There is, of course, a trade-off between the blunt and sharp tip geometries. As the leading edge of the sampler becomes sharper, the volume of the fluid that enters the sampler tip, but does not enter the sampler tube, increases. This causes additional disturbance for subsequent sampling. 


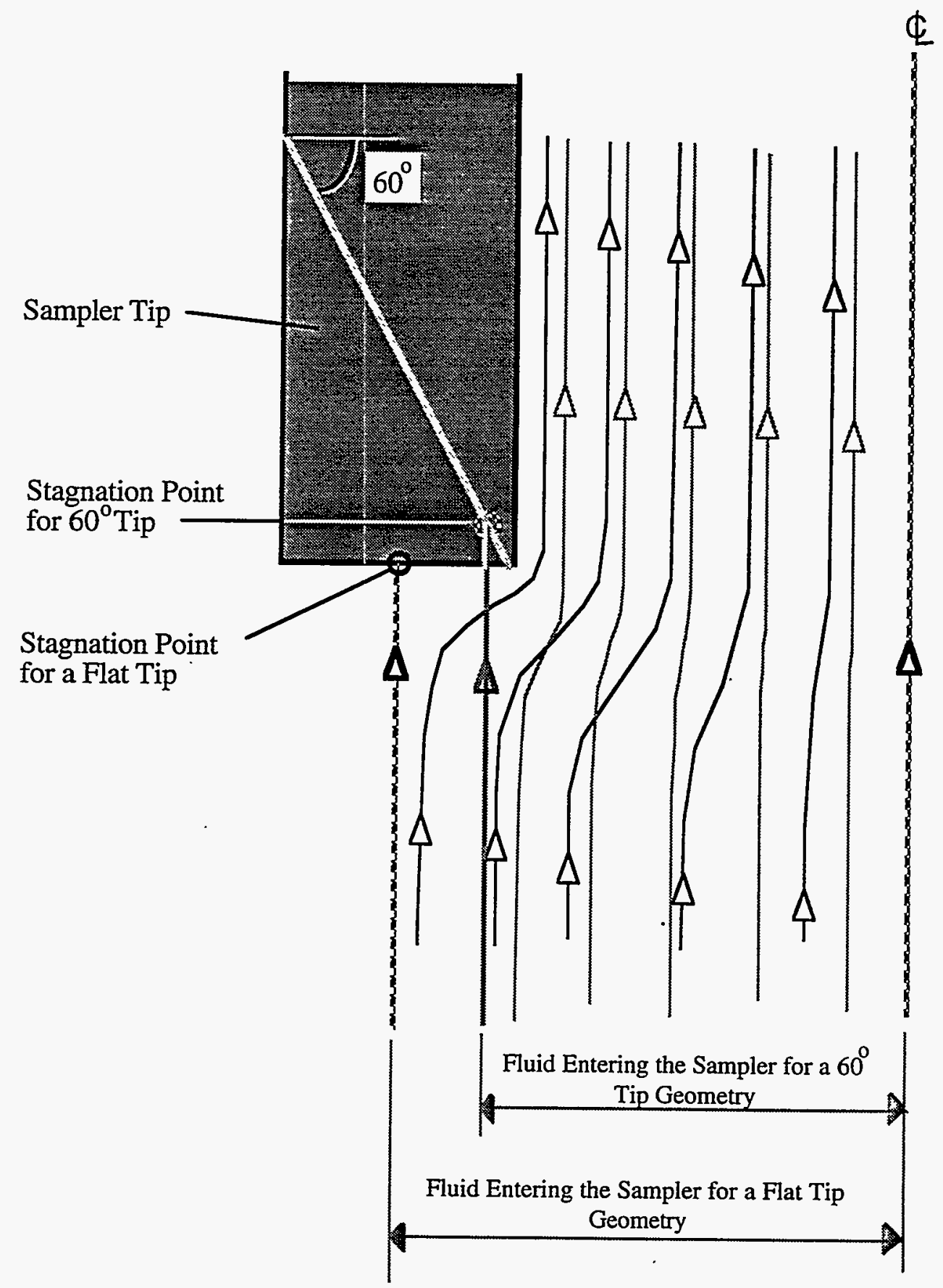

Figure 5. Approximate Streamlines and Location of the Leading Edge Stagnation Points Shown for the Flat Tip and $60^{\circ}$ Tip Geometries, Based on the Video Images (Note that the sampling cross-sectional area has been reduced for the sharper leading edge) 


\subsection{Conclusions}

A set of criteria is established for determining the performance of the sampler:

- The influence of the sampler on the fluid upstream should be minimized in order to minimize disturbance of the state of the waste before and during the sampling.

- The sampling cross-sectional area, $\mathrm{A}_{\mathrm{f}}$, should be minimized.

Based on the current set of visualization studies, it was observed that the $60^{\circ}$ sampler tip geometry produces the more desirable condition insofar as sampling performance is concerned. 
, 


\subsection{References}

Shekarriz, A. May 26, 1994. Retained Gas Sampler Visualization-(Phase II).

Video \#3919/M2, PNL-SA-24390, prepared by Pacific Northwest Laboratory, Richland, Washington, for Westinghouse Hanford Company.

White, F. M. 1977. Viscous Fluid Flow. McGraw-Hill, New York. 


\section{Distribution}

No. of

Copies

12 DOE/Office of Scientific and Technical Information

K. Pasamehmetoglu

Los Alamos National Laboratory

P.O. Box 1663

MS-K555

Los Alamos, NM 87545

B. C. Hudson

202 Northridge Port

Linsborg, KS 67456

\section{ONSITE}

3 DOE Richland Operations Office

Reading Room, A1-65

E. M. Mattlin, S7-54

R. O. Puthoff, A5-10
No. of

Copies

9 Westinghouse Hanford Company

G. D. Johnson, S7-15 (5)

N. G. McDuffie, S7-15

B. J. Webb, S4-58

R. C. Knight, L6-38

D. J. Sherwood, S7-15

25 Pacific Northwest Laboratory

W. J. Apley, S7-71

J. M. Bates, K7-15

R. M. Bean, P8-08

S. Q. Bennett, K7-90

J. W. Brothers, K5-22 (5)

J. B. Colson, K5-10

E. J. Eschbach, K7-15

B. M. Johnson, Jr., K1-78

R. Shekarriz, K7-15 (5)

C. W. Stewart, K7-15

D. M. Strachan, K2-44

Publishing Coordination

Technical Report Files (5)

Distr.1 